\title{
Selecting the Rational Structures of the Usage of Tomato's Production Factors
}

\author{
Mariana Nikolla ${ }^{1}$, Jonida Bou Dib (Lekocaj) ${ }^{1 *}$, Majlinda Belegu ${ }^{1}$ and \\ Xhevaire Dulja ${ }^{1}$
}

\begin{abstract}
The use of mathematical models in financial and economic analysis of the impact of factors on agricultural productivity growth is a priority in the contemporary developments of the agricultural sector. The main purpose of this study is the selection of the best structure for the use of production factors in the cultivation of four different varieties of tomato (Merit, Fine, Samos and Laura) in the greenhouses using a multivariate mathematical model. Hence, our research is focused in identifying and analyzing the most important factors affecting the level of greenhouse tomato culture productivity in 16 municipalities of Lushnja district. Based on the level of importance, the correlation analysis listed those factors: manure (0.369), fertilizer (0.149), water (0.189), and liquid crystalline fertilizer (0.096). Moreover, focusing on the actual levels of production factors used by each municipality, we estimated the maximum yield $(113 \mathrm{q} /$ are $)$, and the most likely production that could be achieved $(100 \mathrm{q} /$ are $)$, based on a rational use of factors. On the basis of the obtained results, the maximum unused reserves were calculated for each municipality in the district of Lushnja. The obtained results constitute a strong basis for budgeting and forecasting activities not only for the tomato crop but also for other agricultural cultures cultivated in other municipalities in the district of Lushnja and in Albania.
\end{abstract}

Keywords: Lushnja district, multivariate model, optimization, rates of substitution, rational variants, tomato.

\section{Introduction}

Often is spoken for an optimization in agriculture or in other sectors of the economy.

Finding the optimum is directly connected with the use of mathematical methods Luptacik, (2004). Today there are many mathematics methods that deal with the theory of Optimization such as the theory of programming, graphs, the 
production model, etc. Moreover, factors like soil fertility, labor, seed quality, climate and technology process, play an important role in the agricultural productivity. These factors directly influence the outcome of the production and are associated with the impact of each other. To determine the optimal level of production in agriculture is necessary to determine the relationship between economic outcome indicators, such as productivity, production factors and cost. On the other hand to build the mathematical models, the factual data are needed, that are subject to experimental analysis and statistical processing.

Sustainable development of agriculture in our country requires not only an increase of production at the farm level, but also an increase in their economic efficiency. Good crop yields and higher productivity of animals are among the most important factors to reduce production costs and provide higher profits. Roughly half of agricultural and livestock production costs are constant in relation with the level of production while land costs, depreciation of machinery and equipment, the costs of planting and crop cultivation, animal housing and maintenance costs and other similar elements, remain unchanged. As a result, unit costs are lower on farms with high production because overall costs and other costs are distributed to more constant production unit. Farms with high production efficiency are more successful because of three factors.

$\checkmark$ Low cost per unit of output;

$\checkmark$ The effective size of the farm;

$\checkmark$ The effectiveness of the use of labor and machinery.

In 1990 the area planted with vegetables amounted to 27,000 ha or about $5 \%$ of the total area, which accounted for 1,100 ha greenhouses and of these about 200 ha were covered with glass greenhouses and heating. Production at this year amounted to 392,000 tons, of which 98,000 tons were taken from the greenhouses. After 90s, the greenhouse area was reduced to only 320 ha in 1993 and rose in 2012 to 828 ha, of which 137 ha are heating and glass. In 2012 the vegetables account at $10 \%$ of arable land, or about 30,813 ha or about $6 \%$ compared with the reference year (1990). In the last 22 years total production of vegetables amounted to 671 thousand tons from 400 thousand tons produced in 1990. Vegetables are grown throughout the country by increasing the average family income in more than $20 \%$. Frontline crops cultivated in Albania are: tomato, cucumber, melon, pepper, leguminous (fresh and dried), eggplant, carrot, onion, garlic, spinach and green lettuce.

Tomato culture ranks first and accounts for about $30 \%$ of the area planted with vegetables, followed by the pepper with $15 \%$ and garlic, onion and the eggplant by about $5 \%$ each. Average yields are about $185 \mathrm{q} / \mathrm{ha}$ in open field and $800 \mathrm{q} / \mathrm{ha}$ in greenhouses. Tomato crops has increased by $10 \%$ as well as some of the large area of the greenhouses that occupies the product, making its price falling 
markets compared to the time when a part of the market covered by imported products. The good quality of the Albanian production has increased the requirements for exports abroad, and Lushnja farmers reported that they have entered into contracts for export with neighboring countries.

One of the basic indicators for increasing the yield of agricultural crops, including tomatoes, is the recognition and effective use of internal resources of the economy of agricultural farms. The determining of production factors, that have a direct and multiple impact on the internal reserves growth, plays an important role in the increase of the agricultural productivity. The correlation between the performance of an agricultural crop and the factors that influence its growth shows the importance of the recognition of study and to determine ways to exploit a profitable quantitative use in achieving the main goal.

Thus, given the importance of the culture of tomato, both for its nutritional values and the processing industry were identified and analyzed the most important factors affecting the level of greenhouse tomato culture productivity in 16 municipalities of Lushnja district.

Figure 1: The area of the research study ${ }^{1}$

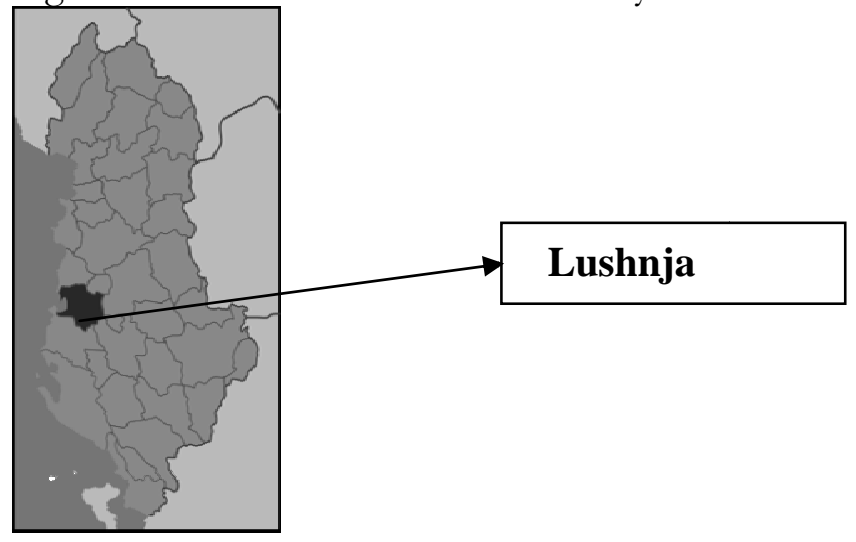

\section{Materials and Methods}

In order to achieve the purpose of the study, factors such as manure, fertilizer, liquid crystalline fertilizers, pesticides ( $\mathrm{q} /$ are) and irrigation $\left(\mathrm{m}^{3} /\right.$ are) were identified as the main factors that contribute on the tomato productivity. Questionnaires were conducted in different farms that cultivate Merit, Fine, Samos and Laura varieties of tomato in 16 municipalities of Lushnja district as well as data from the Regional Directorate of Agriculture and Food in Fier were

\footnotetext{
${ }^{1}$ http://en.wikipedia.org/wiki/File:Lushnj\%C3\%AB District.svg
} 
collected. Moreover, the rates of substitution of the factors in nature and value were calculated. Based on the results a multivariate model was built in order to select the best structure of the use of production factors and measure the maximum and the most possible tomato yields.

\section{Results and Discussion}

The factual yields of tomato and the quantities of the production factors gathered from 16 municipalities of the district of Lushnja were the first findings of our research. Those data are included in Table I below:

Table 1: Data on the tomato yield and use of factors in Lushnja district

\begin{tabular}{|c|c|c|c|c|c|c|}
\hline Municipalities & $\begin{array}{c}\text { Yield } \\
\text { (q/are) }\end{array}$ & Manure & $\begin{array}{c}\text { Fertiliz } \\
\text { er }\end{array}$ & $\begin{array}{c}\text { Liquid } \\
\text { Crystalline } \\
\text { fertilizer }\end{array}$ & Pesticides & $\begin{array}{c}\text { Irrigatio } \\
\mathrm{n} \\
\left(\mathrm{m}^{3} / \text { are }\right)\end{array}$ \\
\hline$K$ & $Y$ & $\boldsymbol{X}_{1}$ & $\boldsymbol{X}_{2}$ & $\boldsymbol{X}_{3}$ & $\boldsymbol{X}_{4}$ & $\boldsymbol{X}_{5}$ \\
\hline Lushnjë & 91 & 90 & 1.6 & 1.5 & 0.06 & 55 \\
\hline Divjakë & 86 & 90 & 1.7 & 1.6 & 0.65 & 50 \\
\hline Karbunarë & 85 & 100 & 1.5 & 1.5 & 0.07 & 55 \\
\hline Fier-Shegan & 85 & 80 & 1.6 & 1.7 & 0.07 & 50 \\
\hline Allkaj & 86 & 90 & 1.8 & 1.4 & 0.07 & 40 \\
\hline Krutje & 85 & 100 & 1.5 & 1.5 & 0.65 & 40 \\
\hline Bubullimë & 80 & 80 & 1.4 & 1.4 & 0.07 & 45 \\
\hline Kolonjë & 80 & 80 & 1.5 & 1.7 & 0.07 & 50 \\
\hline Gradisht & 85 & 100 & 1.5 & 1.4 & 0.06 & 55 \\
\hline Remas & 83 & 100 & 1.5 & 1.4 & 0.06 & 50 \\
\hline Tërbuf & 80 & 90 & 1.8 & 1.3 & 0.65 & 50 \\
\hline Dushk & 82 & 90 & 1.4 & 1.5 & 0.07 & 50 \\
\hline Golem & 78 & 90 & 1.8 & 1.5 & 0.65 & 45 \\
\hline Grabian & 84 & 85 & 1.7 & 1.6 & 0.07 & 50 \\
\hline Hyzgjokaj & 82 & 100 & 1.8 & 1.5 & 0.076 & 50 \\
\hline Ballagat & 75 & 80 & 1.4 & 1.5 & 0.07 & 50 \\
\hline Average & 82.938 & 90.313 & 1.594 & 1.500 & 0.214 & 49.063 \\
\hline Total & 1327 & 1445 & 25.5 & 24 & 3.416 & 785 \\
\hline
\end{tabular}

Source: Data elaborated by the author

The correlation between the performance of an agricultural crop and the factors that influence its growth, show the importance of the recognition of study and to determine ways to exploit profitable their quantitative use in achieving the ultimate goal (Osmani, 2005). Correlative analysis on the impact of each factor in 
tomato production, listed in order of importance: $\mathrm{X}_{1}$ manure $=0.369, \mathrm{X}_{2}$ fertilizer $=0.149, \mathrm{X}_{5}$ water $=0.189, \mathrm{X}_{3}$ crystalline fertilizer $=0.096$.

In order to analyze the yield of tomato culture a multivariate mathematical model was applied (Klejner, G.B., 1978, Rubinov, A.M.1983, Pllakunov, M.K., Rajackas, R.LL.1984, and Cuko, 1987).

$$
y=a_{0} x_{1}^{a_{1}} x_{2}^{a_{2}} x_{3}^{a_{3}} x_{4}^{a_{4}} x_{5}^{a_{5}}
$$

Where $a_{i}$ for $i=1,2,3,4,5$ are the parameters of the model. These parameters express the effective use of relevant factors in such way that their calculation provides the maximum pottential in their assessment. The maximum values of the parameters $a_{i}$ are calculated based on this formula:

$$
a_{i}=p_{i} \max _{k}\left\{\frac{\log \frac{y_{k}}{a_{0}}}{\log x_{k i}}\right\} \text {, }
$$

Where, $p_{i}=\frac{r_{y x_{i}}}{\sum_{i=1}^{5} r_{y x_{i}}}$ and $a_{0}=\frac{\bar{y}}{\prod_{i=1}^{5}\left(\overline{x_{j}}\right)^{p_{i}}}, \mathrm{j}=1-5$

From further calculation we received these results:

$\mathrm{p}_{1}=0.537 \mathrm{p}_{2}=0.216 \mathrm{p}_{3}=0.140 \mathrm{p}_{4}=-0.167 \mathrm{p}_{5}=0.274$

$\mathrm{a}_{0}=32.602 \quad \mathrm{a}_{1}=0.1224 \quad \mathrm{a}_{2}=0.5919 \quad \mathrm{a}_{3}=0.4773 \quad \mathrm{a}_{4}=0.0274 \quad \mathrm{a}_{5}=0.0722$

Based on these values, this multivariate model was built:

$$
\mathbf{Y}=32.602 \mathbf{x}_{1}{ }^{0.1224} \mathbf{x}_{2}{ }^{0.5919} \mathbf{x}_{3}{ }^{0.4773} \mathbf{x}_{4}{ }^{0.0274} \mathbf{x}_{5}{ }^{0.0722}
$$

Focusing on the actual levels of production factors used by each municipality, the maximum yield that can be achieved on the basis of a more rational use of factors was estimated. The differences between the actual yield and yield provide the maximum unused reserves. On the basis of the obtained results, the maximum unused reserves were calculated for each municipality in the district of Lushnja.

Calculating the maximum reserve is important, because they show the potential of production for each municipality, even though, their full use cannot be achieved. 
Municipalities with better results were called municipalities with higher than average yield. Use of these resources is available to a greater extent because their calculation is based not on the highest score of a municipality, but in a few municipalities. In this case the calculation of parameters $a_{i}$ is done with this formula:

$$
a_{i}=p_{i} \text { mes }_{p}\left\{\frac{\log \frac{y_{k}}{a_{0}}}{\log x_{k i}}\right\} \text { where } \operatorname{mes}_{p}\left\{\frac{\log \frac{y_{k}}{a_{0}}}{\log x_{k i}}\right\} \text { is the ratio average } \frac{\log \frac{y_{k}}{a_{0}}}{\log x_{k i}}
$$

greater than their overall average. These ratios fulfill the condition of:

$$
\frac{\log \frac{y_{k}}{a_{0}}}{\log x_{k i}} \geq \frac{\log \frac{y_{k}}{a_{0}}}{\log x_{k i}}
$$

From our calculations we received these results:

$\mathrm{p}_{1}=0.214 \mathrm{p}_{2}=2.409 \mathrm{p}_{3}=2.855 \mathrm{p}_{4}=-0.193 \mathrm{p}_{5}=0.252$

$a_{1}=0.1151 \quad a_{2}=0.5201 \quad a_{3}=0.3983 \quad a_{4}=0.0322 \quad a_{5}=0.0692$

and we designed this multivariate model:

$$
\mathrm{Y}=32.602 \mathrm{x}_{1}{ }^{0.1151} \mathrm{x}_{2}{ }^{0.5201} \mathrm{x}_{3}{ }^{0.3983} \mathrm{x}_{4}{ }^{0.0322} \mathrm{x}_{5}{ }^{0.0692}
$$

Using the above models it is possible to calculate the respective stocks that affect cost reduction, as a difference between the actual cost of production factors of each municipality, with the minimum possible cost. The minimum and most possible cost were calculated using the below formulas ${ }^{2}$ :

$$
Z_{\min }=\frac{\sum_{i=1}^{n} c_{i} x_{i}}{y_{\max }} \text { and } Z_{\text {mund }}=\frac{\sum_{i=1}^{n} c_{i} x_{i}}{y_{\text {mund }}}(6)
$$

Where $c_{i}$ are the prices per unit for the factors $x_{i}(A L L / q)$.

${ }^{2} \mathrm{z}_{\text {mund }}$ (The most possible cost) 
As is cited in Mece et al (2007), an important aspect in the calculation of internal resources is the fair and quantitative harmonization of the factors that affect the growth of the agricultural crops yield. The same performance, but with lower costs can be achieved by relying on the ability that different factors have to replace each other. Thus, fertilizer can be replaced with organic fertilizer or vice versa, but since their prices are different, between them can be set up such reports that reduce the production costs without diminishing the existing yield. For this it is necessary to calculate the rates of mutual substitution of production factors.

If $x_{i}$ factor is reduced or increased with a unit, then it can be replaced with an increase or reduction of $\mathrm{D}_{\mathrm{xji}}$ unit $\mathrm{x}_{\mathrm{j}}$ factor. This amount is called the rate of substitution of factor $\mathrm{x}_{\mathrm{i}}$ with $\mathrm{x}_{\mathrm{j}}$ factor. So, if the amount of manure $\left(\mathrm{x}_{1}\right)$ is reduced with a unit, this reduction can be compensated by adding the chemical fertilizers $\left(\mathrm{x}_{2}\right)$ with $\mathrm{D}_{\mathrm{xji}}$ unit, to obtain the same performance. For this it is necessary to calculate the rates of factors substitution, for example factor $x_{i}$ with factor $x_{i}$. The formula for this calculation is as follows:

$$
D_{x j i}=\overline{x_{j}}\left[\left(\overline{\overline{x_{i}}}\right)^{\frac{a_{i}}{a_{j}}}-1\right] \quad D_{x j i}=\overline{x_{j}}\left[\left(\overline{\overline{x_{i}}}\right)^{\frac{a_{i}}{\bar{x}_{j}}}-1\right]
$$

$\overline{x_{i}} \rightarrow$ the average of $\mathrm{i}$-factor, $\overline{x_{j}} \rightarrow$ the average of $\mathrm{j}$-factor,

$a_{i}, a_{j}$ - the coefficient of the relevant factors.

Table 2 below presents the maximum rates of substitution of factors expressed in natural measurement unit $(\mathrm{N})$ and value $(\mathrm{V})$.

Table 2: The rates of substitution of factors expressed in natural measurement unit $(\mathrm{N})$ and value $(\mathrm{V})$.

\begin{tabular}{|c|c|c|c|c|c|c|c|c|c|c|c|}
\hline \multirow{2}{*}{\multicolumn{2}{|c|}{ Factors }} & \multicolumn{2}{|l|}{$\mathrm{X} 1$} & \multicolumn{2}{|l|}{$\mathrm{X} 2$} & \multicolumn{2}{|l|}{ X3 } & \multicolumn{2}{|l|}{$\begin{array}{c}X \\
4\end{array}$} & \multicolumn{2}{|l|}{ X5 } \\
\hline & & $\mathbf{N}$ & $\mathbf{V}$ & $\mathbf{N}$ & $\mathbf{V}$ & $\mathbf{N}$ & $\mathbf{V}$ & $\mathbf{N}$ & $\mathbf{V}$ & $\mathbf{N}$ & $\bar{V}$ \\
\hline \multirow[t]{2}{*}{$\mathrm{X} 1$} & $\mathrm{~N}$ & - & - & 10596.79 & - & 6460.41 & - & - & & 1.1037 & - \\
\hline & $\mathrm{V}$ & - & - & - & 957028 & - & 583459 & & - & - & 99.6796 \\
\hline \multirow[t]{2}{*}{$\mathrm{X} 2$} & $\mathrm{~N}$ & .0037 & & - & - & 2.27 & - & - & & .0040 & - \\
\hline & $\mathrm{V}$ & - & 36.74 & - & - & - & 3.62 & & - & - & .0064 \\
\hline \multirow[t]{2}{*}{ X3 } & $\mathrm{N}$ & .0043 & - & 3.60 & - & - & - & - & 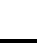 & .0047 & - \\
\hline & $\mathrm{V}$ & - & 8578.21 & - & 5.40 & - & - & & - & - & .0070 \\
\hline \multirow[t]{2}{*}{$\mathrm{X} 4$} & $\mathrm{~N}$ & .0109 & - & 390223098 & - & 4382548 & - & - & . & .0119 & - \\
\hline & $\mathrm{V}$ & - & 6002.30 & - & 83507743 & - & 9378653 & & - & - & .0026 \\
\hline \multirow[t]{2}{*}{ X5 } & $\mathrm{N}$ & .9349 & - & 160378.20 & - & 69920.4 & - & - & & - & - \\
\hline & $\mathrm{V}$ & - & 18.70 & - & 7868635 & - & 3430507 & & - & - & - \\
\hline
\end{tabular}

Source: Data elaborated by the author 
The rates of substitution of factors indicate that for the tomato production, in value more profitable appears the use of manure than other factors. The rates of substitution help to build rational alternatives for the use of production factors. The main criteria derived from these rates and that serves to develop these variants is as follow: at the beginning is necessary to use the entire beneficial factors, while the other factors are used to the quality of the participants, taking care to maintain the minimum ratios between factors.

Table 3: Data on potential yields and production costs of tomato cultivated in greenhouses of Lushnja District

\begin{tabular}{|c|c|c|c|c|c|c|c|c|c|c|}
\hline \multirow[b]{2}{*}{ Names } & \multirow[b]{2}{*}{$\begin{array}{c}\text { Fa } \\
\text { ctua } \\
1 \\
\text { yield } \\
\text { (q/ } \\
\text { are) }\end{array}$} & \multirow[b]{2}{*}{$\begin{array}{c}\text { Ma } \\
\text { ximal } \\
\text { possi } \\
\text { ble } \\
\text { yield }\end{array}$} & \multirow[b]{2}{*}{$\begin{array}{c}\text { Mo } \\
\text { st } \\
\text { possi } \\
\text { ble } \\
\text { yield }\end{array}$} & \multicolumn{2}{|c|}{$\begin{array}{l}\text { Reserves } \\
\text { q/are }\end{array}$} & \multirow[b]{2}{*}{$\begin{array}{c}\text { Fact } \\
\text { ual } \\
\text { Cost } \\
\text { (AL } \\
\text { L/q) }\end{array}$} & \multirow[b]{2}{*}{$\begin{array}{c}\text { Min } \\
\text { imal } \\
\text { possi } \\
\text { ble } \\
\text { cost }\end{array}$} & \multirow[b]{2}{*}{$\begin{array}{c}\text { Mo } \\
\text { st } \\
\text { possi } \\
\text { ble } \\
\text { cost }\end{array}$} & \multicolumn{2}{|c|}{$\begin{array}{l}\text { Reserves in } \\
\text { ALL/are }\end{array}$} \\
\hline & & & & $\begin{array}{l}\text { Maxi } \\
\text { mum }\end{array}$ & $\begin{array}{c}\text { Mo } \\
\text { st } \\
\text { possi } \\
\text { ble }\end{array}$ & & & & $\begin{array}{l}\text { Maxi } \\
\text { mal }\end{array}$ & $\begin{array}{l}\text { Most } \\
\text { Possi } \\
\text { ble }\end{array}$ \\
\hline $\begin{array}{l}\text { Municipaliti } \\
\text { es }\end{array}$ & $Y_{\text {fact. }}$ & $Y_{\max }$ & $Y_{\mathrm{mm}}$ & $\mathrm{R}_{\max }$ & $\mathrm{R}_{\mathrm{mm}}$ & Z & $Z_{\min }$ & $Z_{\mathrm{mm}}$ & $\mathrm{R}_{\max }$ & $\mathrm{R}_{\mathrm{mm}}$ \\
\hline $\mathrm{K}$ & 1 & 2 & 3 & $4=2-1$ & $5=3-1$ & 6 & 7 & 8 & $9=6-7$ & $10=6-8$ \\
\hline Lushnjë & 91 & 112 & 99 & 21 & 8 & 35199 & 28583 & 32357 & 6616 & 2842 \\
\hline Divjakë & 86 & 127 & 112 & 41 & 26 & 43355 & 29357 & 33162 & 13998 & 10193 \\
\hline Karbunarë & 85 & 110 & 97 & 25 & 12 & 37936 & 29388 & 33115 & 8548 & 4821 \\
\hline Fier-Shegan & 85 & 117 & 102 & 32 & 17 & 42253 & 30710 & 35045 & 11543 & 7208 \\
\hline Allkaj & 86 & 114 & 101 & 28 & 15 & 35003 & 26383 & 29906 & 8620 & 5097 \\
\hline Krutje & 85 & 114 & 102 & 29 & 17 & 41686 & 31084 & 34626 & 10602 & 7060 \\
\hline Bubullimë & 80 & 98 & 88 & 18 & 8 & 37368 & 30582 & 34029 & 6786 & 3339 \\
\hline Kolonjë & 80 & 113 & 99 & 33 & 19 & 44881 & 31897 & 36231 & 12984 & 8650 \\
\hline Gradisht & 85 & 106 & 94 & 21 & 9 & 35519 & 28557 & 32027 & 6962 & 3492 \\
\hline Remas & 83 & 105 & 94 & 22 & 11 & 36373 & 28753 & 32238 & 7620 & 4135 \\
\hline Tërbuf & 80 & 119 & 107 & 39 & 27 & 39119 & 26303 & 29349 & 12816 & 9770 \\
\hline Dushk & 82 & 103 & 92 & 21 & 10 & 39104 & 31049 & 34778 & 8055 & 4326 \\
\hline Golem & 78 & 126 & 112 & 48 & 34 & 45249 & 27917 & 31494 & 17332 & 13755 \\
\hline Grabian & 84 & 119 & 104 & 35 & 20 & 40488 & 28666 & 32713 & 11822 & 7775 \\
\hline Hyzgjokaj & 82 & 122 & 107 & 40 & 25 & 39400 & 26555 & 30297 & 12845 & 9103 \\
\hline Ballagat & 75 & 102 & 91 & 27 & 16 & 42527 & 31333 & 35065 & 11194 & 7462 \\
\hline Average & 83 & 113 & 100 & 30 & 17 & 39716 & 29195 & 32902 & 10521 & 6814 \\
\hline Total & 1327 & 1806 & 1602 & 479 & 275 & 635459 & 467115 & 526432 & 168344 & 109027 \\
\hline
\end{tabular}

Source: Data elaborated by the author

Using and relying on the data stated above on Table 1 and Table 3 and the results obtained from the model, the below production factors variants can be built. 
Table 4: Choosing the rational alternatives for the use of production factors.

\begin{tabular}{|c|c|c|c|c|c|c|c|}
\hline \multirow[t]{2}{*}{ Factors } & \multicolumn{3}{|c|}{ Variables } & \multirow[t]{2}{*}{ Factors } & \multicolumn{3}{|c|}{ Variables } \\
\hline & 1 & 2 & 3 & & 1 & 2 & 3 \\
\hline$\overline{X_{1}}$ & 100 & 100 & 100 & $\overline{X_{1}}$ & 100 & 100 & 100 \\
\hline $\mathrm{X}_{2}$ & 1.4 & 1.42 & 1.6 & $\mathrm{X}_{2}$ & 1.579 & 1.83 & 1.63 \\
\hline $\mathrm{X}_{3}$ & 1.65 & 1.341 & 1 & $\mathrm{X}_{3}$ & 1.5 & 1.68 & 1.7 \\
\hline $\mathrm{X}_{4}$ & 0.06 & 0.07 & 0.31 & $\mathrm{X}_{4}$ & 0.07 & 0.08 & 0.413 \\
\hline $\mathrm{X}_{5}$ & 53 & 50 & 55 & $\mathrm{X}_{5}$ & 55 & 52 & 54 \\
\hline $\begin{array}{c}\text { Most } \\
\text { possible } \\
\text { yield }\end{array}$ & 100 & 100 & 100 & $\begin{array}{l}\text { Maximal } \\
\text { Yield }\end{array}$ & 113 & 113 & 113 \\
\hline $\begin{array}{c}\text { Expenditur } \\
\text { es } \\
\text { (000ALL) }\end{array}$ & $\begin{array}{c}29480 \\
60\end{array}$ & $\begin{array}{c}29057 \\
00\end{array}$ & $\begin{array}{c}23582 \\
00\end{array}$ & $\begin{array}{c}\text { Expenditur } \\
\text { es } \\
\text { (000ALL) }\end{array}$ & $\begin{array}{c}32253 \\
90\end{array}$ & $\begin{array}{c}35933 \\
40\end{array}$ & $\begin{array}{c}38145 \\
30\end{array}$ \\
\hline Cost $/ \mathrm{q}$ & 29481 & 29057 & 23582 & Cost $/ q$ & 28543 & 31800 & 33757 \\
\hline
\end{tabular}

Source: Data elaborated by the author

The third option can not be accepted because the use of liquid crystalline fertilizer is off limits to the actual variation ( $1 \mathrm{q} /$ are), which disrupts the relationship between liquid crystalline fertilizer and other factors. We can use the first or second version, in which the manure is used in maximum level $100 \mathrm{q} /$ are. In these conditions, to achieve the highest possible efficiency is using less fertilizer and holding crystalline manure in minimum levels, but not outside of the actual variation. Water is kept at almost maximum levels of actual use. For the first variant, cost is estimated at 29,481 $\left(\mathrm{ALL}^{3} / \mathrm{q}\right)$, while the second version cost is 29,057 (ALL/q). Under these conditions the most probable total reserves in reducing the cost per unit for the first variant is calculated: $\mathrm{R}=39,716$ $29,481=10,235$ (ALL/q). As for the second version, the total potential reserves are calculated as follows: $\mathrm{R}=39,716-29,057=10,659(\mathrm{ALL} / \mathrm{q})$. Based on these results, the best combination of factors for the first version can be calculated $R_{h}$ $=10,235-6,814=3,421(\mathrm{ALL} / \mathrm{q})$ or $\mathrm{R}_{\mathrm{h}}=32,902-29,481=3,421(\mathrm{ALL} / \mathrm{q})$ and the reserves in ALL/q for the second version are: $\mathrm{R}_{\mathrm{h}}=10,659-6814=3,845(\mathrm{ALL} / \mathrm{q})$ or $\mathrm{R}_{\mathrm{h}}=32,902-29,057=3,845$ (ALL/q).

To continue with, the maximum reserves related to a better harmonization of the quantitative factors, can be calculated in the same way. The data in Table 4 above show that, the second option cannot be used because the use of liquid crystalline fertilizer is off limits to the actual variation, which disrupts the relationship between crystalline fertilizer and other factors. The first option is more profitable where the manure and crystalline manure are in their maximum limits of use, or close to it. Water factor is kept at its maximum factual condition.

${ }^{3} 1 \mathrm{ALL}=0.0072 \mathrm{EUR}$ (December 2012) 
The cost for 1 quintal, as can be seen from the results in the table above is 28 , 543 (ALL/q). However, the third option can be used also where the cost for 1 quintal turns 33,757 (ALL/q) which is higher than the cost of the first option. In such conditions the total reserves in reducing the cost per unit for the first option is: $\mathrm{R}=39,716-28,543=11,173(\mathrm{ALL} / \mathrm{q})$. As for the third option: $\mathrm{R}=39,716-$ $33,757=5,959$ (ALL / q). Following those results, for the first option the best combination of factors can be calculated as follow: $R_{h}=11,173$ $10,521=6,52$ (ALL/q) or $R_{h}=29,195-28,543=652$ (ALL/q). While, the respective reserve for the third option in ALL/q are: $R_{h}=10,521-5,959=4,592($ ALL/ $q$ ) or $\mathrm{R}_{\mathrm{h}}=33,757-29,195=4,592(\mathrm{ALL} / \mathrm{q})$. Knowing the reserves and in specific the ones that come out from the deficiencies in the harmonization of factors, helps out in yield agricultural crops assess and costs planning.

Moreover, based on the quantities that a farm has for each production factor, through the above models we are able to measure the maximal and the most possible yield, e.g. if the farm has these quantities of production factors: $\mathrm{X}_{1}=95 \mathrm{q} /$ are, $\mathrm{X}_{2}=1.7 \mathrm{q} /$ are, $\mathrm{X}_{3}=1.4 \mathrm{q} /$ are, $\mathrm{X}_{4}=0.7 \mathrm{q} /$ are, $\mathrm{X}_{5}=60 \mathrm{~m}^{3} /$ are, so the maximal yield that can be achieved is $121.78 \mathrm{q} /$ are, with a minimum cost of 27,627.46 ALL/q, while the most possible yield is $108.89 \mathrm{q} /$ are, with the most possible cost of 30,899.6 ALL/q.

These results are a good basis for the calculation of farm income as a result of this agricultural crop cultivation. Such analysis, using the above models, can be used not only for other agricultural crops cultivated in agricultural farms, but also in the livestock sector.

\section{Conclusions}

The use of mathematical models in financial and economical analysis of the factors in the increase of agricultural productivity, is a priority in the contemporary developments of agricultural sectors. From the data analysis we found out that the average productivity was increased by $17 \mathrm{q} /$ are or $30 \%$, while in specific municipalities such as Golem by $38 \%$, Terbuf about $33 \%$ and in Divjake about $32 \%$. On the other hand, in terms of the cost of tomato production, the reserves were substantial, about $21 \%$, while in other municipalities the reserves for reducing the cost of tomatoes have been even greater as: Divjake 31\%, 24\% in Kolonje , and in Terbuf 33\%. The rates of substitution help to design the rational alternatives for the use of production factors. The main criteria derived from these rates and that serves to develop these variants is as follow: At the beginning is necessary to use the entire beneficial factors, while the other factors are used to the quality of the participants, taking care to maintain the minimum ratios between factors. Based 
on the data in Table 2 and 3 a more economic and suitable options can be built in order to achieve the maximum and the most possible production yield. Furthermore, based on the quantities that a farm has for each production factor, through the above models we are able to measure the maximal and the most possible yield, e.g. if the farm has these quantities of production factors: $\mathrm{X}_{1}=95 \mathrm{q} /$ are, $\mathrm{X}_{2}=1.7 \mathrm{q} /$ are, $\mathrm{X}_{3}=1.4 \mathrm{q} /$ are, $\mathrm{X}_{4}=0.7 \mathrm{q} /$ are, $\mathrm{X}_{5}=60 \mathrm{~m}^{3} /$ are, so the maximal yield that can be achieved is $121.78 \mathrm{q} /$ are, with a minimum cost of 27,627.46 ALL/q, while the most possible yield is $108.89 \mathrm{q} /$ are, with the most possible cost of 30,899.6 ALL/q.

The same model can be used efficiently to make such analysis for other crops in the agricultural sector, in farming and in other areas of the economy.

The obtained results constitute a strong basis for budgeting and forecasting activities not only for the tomato but also for other agricultural cultures for each municipality in the district of Lushnja and in Albania.

\section{References}

Çuko, R. (1987). "Mbi vleresimin e parametrave te funksioneve te prodhimit". (Evaluating the variables of production function), Buletin i Shkencave Natyrore, Nr.1, 37-48.

Klejner, G.B., (1978). “Область Определения производственной функции, Экономика и Математическая методы”, (The domain of production function, the economy and mathematics models), Vol.5, 932-941.

Luptacik, M (2004), Mathematical Optimization and Economic Analysis, Vol. 36.

Mece, M. Sulo, R and Leksinaj, E. (2007), "Drejtim Fermash" (Farms Management), Dita 2000, Tirana.

Osmani, M. (2005), "Metodat e Ekonometrise" (Econometrics Methods), Tirana.

Pllakunov, M.K., Rajackas, R.LL., (1984). "Производственные функции у экономический анализ" (Production function in economic analysis), Vilnjus, MINTIS, 17-24.

Rubinov, A.M. (1983). "Математическая модель расширенного воспроизводства", (Mathematical model of expanded reproduction), L. Nauka, 16-19. 
